\title{
Antimalarial, antioxidant, antimicrobial properties of Moringa Oliefera Lam: A review
}

\author{
Abdulaziz Rabiu Abdulkadir ${ }^{1}$, Md Mainul Hasan ${ }^{2}$, Md Sarwar Jahan $^{1 *}$ \\ ${ }^{1}$ Faculty of Bioresources and Food Industry, Universiti Sultan Zainal Abidin, 22200, Besut, Terengganu, 22200 \\ Malaysia \\ ${ }^{2}$ Department of Agricultural Botany, Faculty of Agriculture. Patuakhali Science and Technology University, Dumki, \\ Patuakhali, 8602 Bangladesh
}

*Corresponding author:: sarwarjahan@unisza.edu.my

\begin{abstract}
Moringa oliefera Lam (Moringa) has antimalarial, antioxidant, antimicrobial as well as nutritional properties. Different parts of Moringa was used as a folk medicine to cure certain diseases ranging from venomous bites, rheumatism, ascites, circulatory stimulant among. Previous studies showed that different parts of Moringa oleifera have shown various pharmacological properties. However, there is a gap where substantial information is to be updated in the area of antimalarial, antioxidant, antimicrobial effect of the plants. Nevertheless, some part of the plant such as leaves and fruits have been used as vegetables, which serve as an excellent source of vitamins, beta-carotene, calcium, iron, riboflavin and phenolic acid. Therefore, there is an affirmative action that the plant has a vast antimalarial, antioxidant, antimicrobial activity to cure different diseases.
\end{abstract}

Keyword: Moringa oleifera, amalaria, tumor, antibacterial, diabetes.

Introduction

Moringa oleifera Lam. belongs to the Caricaceae family (Bennette et al., 2003) and is a versatile plant, popularly called drumstick, horseradish or ben oil tree (Fahey, 2005). It is also known as a miracle tree, excellent plant, general purpose plant because all parts of the plant are necessary for the human. However, some of the beneficial effects of Moringa plants are medicine, nutrition, livestock feed, landscaping, and water management, and it is widely cultivated species is Moringaceae family (Bennette et al., 2003). However, it is an important plant to South, East and West Africa, Latin America, tropical Asia, Caribbean, Pacific Islands and Florida among others (Fahey, 2005). Some part of the plant such as leaves, fruits, roots and flowers has long been used as vegetables (Siddhuraju and Becker, 2003). Leaves contain vitamins, calcium, iron, riboflavin, beta-carotene, and phenolic acid among others (Lalida et al., 2013). However, Fahey (2005) added that the protein quality of leaves of Moringa exceeds than that of egg and milk. The pods are an important source of fibre (Dillard and German, 2000). Nevertheless, the oil from seed has been used as a remedy to skin diseases and curing inflammatory disorder (Villasenor, 1994). The flowers have hypocholesterolemic properties therefore it is consumed as a tea (Lalida et al., 2013). Moringa is a rich source of many bioactive compounds, such as phenolic compounds, alkaloids, phytosterols, terpenoids and tannins. Some of them are used for medicinal purposes including anti-ulcer (Dahiru et al., 2006), analgesic (Sutar et al., 2008), hepatoprotective activity against liver damage (Pari and Kumar 2002), malnutrition (Fahey, 2005), Antioxidant and hepatoprotective (Fakurazi et al., 2008), anti-malaria, and anti-diabetes (Chinmoy, 2007), anti-cancer (Fahey, 2005), anti-hypertention (Arora et al., 2012). It was also testified that it contains secondary metabolite known as glucosinolates, which showed anti-tumor properties (Bennette et al., 2003). However, It was reported that Moringa possessed galactagogue property which promotes the secretion of milk, thus help the production of milk in nursing mothers, biogas production, bio pesticides and domestic cleaning agent (Fuglie, 1999).

\section{Medicinal value of Moringa plants}

About $80 \%$ of the Peoples living in a rural community of the world largely depend on traditional medicines for their health. Besides, plant-derived compounds have played key roles in drug discovery. The medicinal value of the parts of Moringa can never be overemphasized, however over an extended period, a different part of the plant was used in folk medicine to cured certain diseases which include venomous bites, rheumatism, ascites and also cardiac and circulatory stimulant among others (Guenera et al., 1996). However, Jamaicans, used the sap as blue dye. Malaysian and Puerto Rico used Moringa against intestinal worms. While Philippines, utilise it as a remedy for glandular swelling, anaemia and lactating problems. Mishra et al. (2012) confirmed that the plants is used as traditional medicine for many purposes that enhance the body health. It composed of many primary and secondary metabolites which have different uses (Croteau et al., 2000). Many compounds in Moringa have been identified for their 
beneficial role (Balandrin et al., 1985). Therefore, several active constituents of Moringa can be used as modern medicine.

\section{Pharmacological properties of Moringa on malaria}

Plant serve as the sources of many conventional drugs: a century ago, nearest most of the effective drugs used to cure malaria were plant based. Such as artemisinin, quinine, reserpine, salicylic acid, sinnoside, texol, vincristine, vinblastine, glycyrrhizin and psoralen (Mukherjee, 2003). Patel et al. (2010) stated that Moringa can be used as effective anti-malaria due to its high content of acetone compound. However, conventional anti-malarial drugs are rapidly losing their effectiveness due to development of resistance capacity of malarial parasites. Nevertheless, Okechukwu et al. (2013) studied that the ameliorative properties of ethanol leaf extract of Moringa oleifera on injured liver and kidney of malaria infected-mice. However, (Obasi and Mba, 2010) revealed the effectiveness of Moringa oleifera leaf extract on animals. They concluded that the extract not only serve as protective against plasmodium infection but also prevent the occurrence of new infections as well as prevent the progression of the disease into a severe attack.

\section{Antioxidant effect of Moringa oleifera}

Antioxidants are substances that protect cells from free radicals which cause DNA damage and possible development of the cancer. Pong (2003) added that oxidative damage causes many chronic human diseases such as cancer, diabetes mellitus, arthritis, atherosclerosis, neurodegenerative diseases as well as in the aging process. The major phenolic compound in the medicinal plant that is associated with antioxidant activities are flavonoids, phenols, tannins, and alkaloids (Bako et al., 2010). Marchioli et al. (2001) reported that epidemiological studies have proven that possibility of cancer and coronary heart diseases reduce the intake of vitamin $C$ which serves as an antioxidant. Sreelatha and Padma (2009) studied antioxidant activities of Moringa leaf extracts, using the standard in vitro models which were tested in two stages of it maturity namely tender and matured leaves. A strong scavenging effect on 2, 2-diphenyl-2-picryl hydrazyl (DPPH) free radical, nitric oxide radical, superoxide, and inhibition of lipid per oxidation were observed from the aqueous extract of Moringa (Abdulkadir et al., 2015a, 2015b and 2015c). Extracts of mature and tender leaves of Moringa oleifera have not only potent antioxidant activity against free radicals but also prevent oxidative damage to major biomolecules and provides significant protection against oxidative damage. Hence, antioxidants of Moringa leave vary according to different stages of the maturity. This was consistent with previous results stated by Singh et al. (2012). They said that antiulcer and antioxidant properties of the leaves of Moringa Oleifera against gastric ulcer in rats, and result revealed the defense mechanism to lipid peroxides and scavenging endogenous reactive oxygen species production. Luqman et al. (2012) discovered variation Antioxidant activities between in vitro and in vivo ethanolic extract of Moringa fruit and leaves in comparison with that of aqueous extract, where aqueous extract showed higher potential in vivo while the ethanolic extract of both fruit and leaf of Moringa was greater in the in vitro condition.

\section{Antimicrobial effects of Moringa oleifera}

Different studies stated that stem, flowers, bark, roots and seeds showed different activities of antimicrobial properties (Fahey, 2005). Moringa oleifera have been considered as an antimicrobial agent after the discovery of several antimicrobial components with inhibitory activity against many microorganisms (Fozia et al., 2012). Although, Oluduro (2012) discovered the weakness of antimicrobial effect of leaves of the Moringa to extract as the inhibition growth zones that unable to reach at $1.5 \mathrm{~mm}$, which implies that the concentration of Moringa leaf extract has used less effect on these organisms. Nevertheless, Urmi et al. (2012) obtained a meaningful result using ethylacetate fraction of bark and fruit as well as chloroform fraction of leaf and fruit of Moringa. Bako et al. (2010) discovered that extracts of Moringa inhibit the growth of certain bacterial and fungal species which are Pseudomonas aeriginosa, Candida albicans, Bascillus subtilis, Staphylococcus aureus, Escherichia coli, and Salmonella typhi. Moringa. leaves have been reported to be an excellent source of phytochemicals products such as flavonoids and phenolic compounds to be worked as antimicrobial properties (Bako et al., 2010). In addition, Torres-Castillo et al. (2013) confirmed that antioxidant activities of the extracts of parts of plants have been related to the polyphenolic compounds that work as antimicrobial agents. It was known that Moringa is a rich source of a compound called pterygospermin, which has powerful antibacterial and fungicidal effects (Ruckmani et al., 1998). Furthermore, leaves contain benzyl isothiocynate, benzyl glucosinolate and other sister compounds that function against bacteria and bacteriostatic activity (Fahey, 2005). In addition, polypeptide compound in plants also proved the bactericidal properties against Legionella, Streptococcus, and Staphylococcus species (Suarez et al., 2003). Recently, Jabeen et al. (2008) demonstrated the antimicrobial properties of Moringa extract against bacterial species.

\section{Nutritional value of Moringa oleifera}

Moringa oleifera serves as an important plant capable of combating malnutrition, especially to nursing mothers and children (Fahey, 2005). It is necessary for good health due to the high content of vitamins, amino acids and minerals. Although leaves, flowers and fresh pods of Moringa were used as vegetables and livestock feed in some countries (Anjorin et al., 2010). Rag Tag Research Geeks (2013) stated that nutritional benefits of Moringa oleifera is higher than vegetables or fruits. Hence, Moringa leaves contain seven times more vitamin $C$ than oranges, four times the calcium than in milk, four times vitamin A than carrots, three times iron than almonds and three times potassium found than bananas.

The new and fresh leaves can be eaten, boiled or even stored as dried powder for a long time without loss of nutritional content or being spoiled (Fahey, 2005). The seeds can be used to produce oil which can serve as a substitute for palm or peanut oil due to its high pleasant taste and oxidative value. While the flowers and leaves were used to 
make tea with high flavonoids content that is essential for the converting free-radicals which are the root causes of many human body problems. The immature pods of Moringa are also widely used to prepared dishes in many localities especially in India (Anwar et al., 2005). Anwar et al. (2005) reported that leaves are used as a regular component of traditional dishes about 5000 years ago in India. However, many of the variations occur in the nutritional values of Moringa oleifera, can be caused by different factors such as environment, genetic background and cultivation methods (Brisibe et al., 2009).

\section{Conclusion}

Above discussion demonstrated that different parts of Moringa oleifera have different therapeutic values against various diseases, and proved the functioning activity for using as traditional medicine. However, several active constituents of Moringa were discovered which ensured its applicability in modern medicine. This plant showed protective effects against plasmodium infection, oxidative related problems and microbial infections due to the presence of many compounds such as flavonoids, tocopherols, vitamin C, and other phenolic compounds. Nevertheless, this plant also showed various nutritional benefits which is higher than that other edible plant food. Hence, more studies are needed to isolate, characterized each active constituents and to determined their therapeutic effects. In addition, extracts would be interested in further research in the field of cancer science and other diseases.

\section{Acknowledgements}

This work was supported by the FRGS funding (FRGS/2/2014/STWN03/UNISZA/02/1) and the Faculty of Bioresources and Food Industry, Universiti Sultan Zainal Abidin, Terengganu, Malaysia.

\section{References}

Abdulkadir AR, Jahan MS, Zawawi DD (2015a) Effect of chlorophyll content and maturity on total phenolic, total flavonoid contents and antioxidant activity of Moringa oleifera leaf (Miracle tree). J Chem Pharm Res. 7:11471152.

Abdulkadir AR, Zawawi DD, Jahan MS (2015b) DPPH antioxidant activity, total phenolic and total flavonoid content of different part of Drumstic tree (Moringa oleifera Lam.). J Chem Pharm Res. 7:1423-1428.

Abdulkadir AR, Zawawi DD, Yunusa AK, Jahan MS (2015c) In Vitro Antioxidant Potential, Total Phenolic Content and Total Flavonoid Content of Methanolic Flower and Seed Extract of Miracle Tree (Moringa Oleifera Lam.). Aust J Basic Appl Sci. 9:27-31.

Anjorin TS, Ikokoh P, Okolo S (2010) Mineral composition of Moringa oleifera leaves, pods and seeds from two regions in Abuja, Nigeria. Int J Agril Bio. 12:431-434.

Anwar F, Ashraf M, Bhanger MI (2005) Interprovenance variation in the composition of Moringa oleifera oil seeds from Pakistan. J Ame Oil Chem Soc. 82:45-51.

Arora DS, Chandra P, Kaur GJ (2012) Optimization essay of antioxidant potential of two Penicillium spp by different procedures. Curr Biotech. 1: 2-10.
Bako SS, Okere JU, Etonihu AC, Mohammed Y, Olanisakin OA, Atolaiye BO, Mau P C (2010) Medicinal values of Moringa oleifera leave extracts. Raw materials research and development council: Moringa - A national crop for economic growth and development. 107-114.

Balandrin MF, Klocke JA, Write ES, Bollinger WH (1985) Natural plant chemicals: Source of industrial and medicinal materials. Sci. 228:1154-1160.

Bennette RN, Mellon FA, Foidl N, Pratt JH, Dupont MS, Perkins L, Kroon PA (2003) Profiling glucosinolates and phenolics in vegetative and reproductive tissues of the multi-purpose trees Moringa oleifera L. (Horseradish tree) and Moringa stenopetala L. J. Agril Food Chem. 57:3546-3553.

Brisibe EA, Umoren UE, Brisibe F, Magalhaes PM, Ferreira JF, Luthria D, Wu X, Prior RL (2009) Nutritional characterization and antioxidant capacity of different tissues of Artemisia annua L. Food Chem. 115:1240-1246.

Chinmoy KB (2007) Possible role of Moringa oleifera lam. Root in epithelial ovarian Cancer. Medcscape General Med. 9:26.

Croteau R, Kutchan TM, Lewis NG (2000) Natural products (Secondary metabolites). In: B. Buchanan, W. Gruissam, R. Jones (Eds.), Biochemistry and Molecular Biology of Plants. 24: $1250-1319$.

Dahiru D, Onubiyi JA, Umaru HA (2006) Phytochemical screening and anti ulcerogenic effect of Moringa oleifera aqeous leaf extract. Afr J Tradit Complement Altern Med. 3:70-75.

Dillard CJ, German JB (2000) Phytochemicals: Nutraceuticals and Human health: A review. . J Agril Food Chem. 12:17441756.

Fahey JW (2005) Moringa oleifera: A review of the Medical evidence for its nutritional, Therapeutic and prophylactic properties. Part 1. Retrieved from Trees for Life Journal website:

http://www.tfljournal.org/article.php/20051201124931586

Fakurazi S, Nanthini U, Hairuszah I (2008) Hepatoprotective and antioxidant action of Moringa oleifera Lam. Against acetaminophen induced hepato toxicity in rats. Int J Pharmacol. 4:270-275.

Fozia F, Meenu R, Avinash T, AbdulArif K, Shahila F (2012) Medicinal properties of Moringa oleifera: An overview of promising healer. J Med Plants Res. 6:4368-4374.

Fuglie $\amalg$ (1999) The miracle tree: Moringa oleifera: Natural Nutrition for the tropics. Church world service, Dakar, pp 68.

Guenera PA, Vergas C, Milagros UY (1996) Anti-inflammatory and anti-tumor activities of seed extracts of Malunggay, Moringa oleifera L. (Moringaceae). Philippine J Sci. 125:175184.

Jabeen R, Shahid M, Jamil A, Ashraf M (2008) Microscopic evaluation of the antimicrobial activity of seed extracts of Moringa oleifera. Pakistan J Bot. 40:1349-1358.

Lalida PS, Thidarat R, Vannajan SL, Srisulak D (2013) Peroxidase activity in native and callus culture of Moringa oleifera Lam. J Med Bioeng. 2: 163-167.

Luqman S, Srivastava S, Kumar R, Maurya AK, Chanda D (2012) Experimental Assessment of Moringa oleifera Leaf and Fruit for Its Antistress, Antioxidant, and Scavenging Potential Using In Vitro and In Vivo Assays. Evidence-Based Complementary and Alternative Medicine: eCAM, 519084. http://doi.org/10.1155/2012/519084.

Marchioli R, Schweiger C, Levantesi G, Tavazzi L, Valagussa F (2001) Antioxidant vitamins and prevention of 
cardiovascular disease: epidemiological and clinical trial data. J Lipid Res. 36:53-63.

Mishra SP, Singh P, Singh S (2012) Processing of Moringa oleifera Leaves for Human Consumption. Bulletin of Environment. Pharmacol Life Sci. 2:28- 31.

Mukherjee PK (2003) Exploring botanicals in indian systems of medicine regulatory Perspectives. Clin Res Regul Aff. 20:249264.

Obasi TC, Mba CC (2010) Moringa oleifera Leaf extract as a protective agent against Malaria (Plasmodium berghei) infection in Rats. Raw materials research and development council: Moringa - A national crop for economic growth and development. 130-136.

Okechukwu UPC, Okwesili NFC, Parker JE, Christian OE, Emmanuel OC, Aburbakar B (2013) Ameliorative effects of ethanol leaf extract of Moringa oleifera on the liver and kidney markers of malaria infected mice. Int J Life Sci Biotechnol Pharma Res. 2:44-46.

Oluduro AO (2012) Evaluation of Antimicrobial properties and nutritional potentials of Moringa oleifera Lam. leaf in SouthWestern Nigeria. Malaysian J Microbiol. 8:59-67.

Pari L, Kumar NA (2002) Hepatoprotective activity of Moringa oleifera on anti- tubercular drug-induced liver damage in rats. J Med Food. 5:171-177.

Patel JP, Bharat G, Patel K (2010) Evaluation of in vitro Schizonticidal Properties of Acetone Extract of some Indian Medicinal Plants. Adv Biol Res. 4, 253-258.

Pong K (2003) Oxidative stress in neurodegenerative diseases: therapeutic implications for superoxide dismutase mime tics. Expert Opin Biol Ther. 3:127-139.

Rag Tag Research Geeks. The Moringa Tree (2013) A Nutritional and Medicinal Powerhouse. Retrieved from Rag Tag Research Geeks website: http://ragtagresearchgeeks.com/the-moringa-tree-anutritional-and-medicinal-powerhouse.

Ruckmani K, Kavimani S, Anandan R, Jayka B (1998) Effect of Moringa oleifera Lam. on paracetamol-induced hepatoxicity. Indian J Pharm Sci. 60: 33-35.
Siddhuraju P, Becker K (2003) Antioxidant properties of various solvent extracts of total phenolic constituents from three different agro climatic origins of drumstick tree (Moringa oleifera Lam.) leaves. J Agril Food Chem. 51:21442155.

Singh N, Kumar V, Saxena P, Singh R (2012) Anti-Ulcer and Antioxidant Activity of Moringa Oleifera (Lam) Leaves against Aspirin and Ethanol Induced Gastric Ulcer in Rats. Int Res Pharm J. 2:46-57.

Sreelatha S, Padma PR (2009) Antioxidant Activity and Total Phenolic Content of Moringa oleifera Leaves in Two Stages of Maturity. Plant Food Human Nut. 64:303-311.

Suarez M, Entenza JM, Doerries C (2003) Expression of a plant derived peptide harbouring water-cleaning and antimicrobial activities. Biotech Bioeng. 81:13-20.

Sutar NG, Bonde CG, Patel VV, Arched SB, Patil AP, Kakade RT (2008) Analgesic activity of Moringa oleifera L. Int J Green Pharm. 2:108-110.

Torres-Castillo JA, Sinagawa-García SR, Martínez-Ávila GC, López-Flores AB, et al. (2013) Moringa oleifera: phytochemical detection, antioxidants, enzymes and antifungal properties. Int J Expt Bot. 82:93-202.

Urmi KF, Masum NM, Zulfiker AM, Hossain MK, Hamid K (2012) Comparative Anti-microbial activity and brine shrimp lethality bioassay of different parts of the plant Moringa oleifera lam. J App Pharm Sci. 2:85-89.

Villasenor I (1994) Bioactive metabolites from Moringa oleifera Lam. Kimilia. 10:47-52. 